\title{
PHYLOGENETIC IMPLICATIONS OF GROOMING BEHAVIOR IN COCKROACHES (INSECTA: BLATTARIA)*
}

\author{
By Bonnie J. Bobula Smith and Barry D. Valentine \\ Department of Zoology, The Ohio State University, \\ Columbus, Ohio 43210-1293
}

\section{INTRODUCTION}

The use of behavioral data for the investigation and delineation of evolutionary relationships has been increasingly heuristic (Evans, 1952; Speith, 1952; Alexander, 1962; etc.). In insects, grooming behavior seems particularly useful because it is a widespread and prominent part of their behavioral repertory. Comparative studies of several orders have been based on grooming behavior (Szymanski, 1918; Heinz, 1949; Gangwere, 1958; Jander, 1966; Farish, 1972; Valentine, 1973; Valentine and Glorioso, 1979). Lipps (1973) provides an excellent review of grooming literature.

The cockroaches are a diverse group with an extensive nontaxonomic literature. There are many descriptions of the general biology of the order (Gould and Deay, 1938; Roth and Willis, 1954, etc.) and of particular species (Qadri, 1938; Rau, 1940; Dow, 1955; Heslop and Ray, 1959, etc.). Roth and Willis (1954) and McKittrick (1964) summarize many such papers, especially on biology. Our taxonomy follows McKittrick (1964), and is summarized in Table 1.

Unspecified grooming behavior of cockroaches is mentioned by Patton (1941) and Burkholder (1965). Others discuss grooming of particular body parts (Haber, 1920; Mote, Wilcox, and Davis, 1926; Roth and Willis, 1952 and 1954; and Eisner, 1961). A few authors are more detailed: Gangwere (1958), Yoshikawa (1958), Eaton and Farley (1969), and Lipps (1973). The most complete description of roach grooming is by Turner (1913), who describes in excellent detail antennal, palpal, and leg cleaning using the mouth, and the use of a leg to rub the base of the antenna and dorsal surface of the abdomen, all in a roach he called Periplaneta orientalis, now placed in the genus Blatta.

*Manuscript received by the editor July 15, 1985. 
The above references give a very incomplete picture of roach grooming. Gangwere (1958) and Lipps (1973) discuss roaches from a generalized view, but the species are not named nor are their individual repertories described. No work investigates the order and tries to characterize grooming patterns within it, and no work describes the complete repertory of even one species.

\section{MeThods}

Grooming behavior was recorded during 154 hours of observations on 23 species representing 20 genera and four families of Blattaria (see Table 1). The grooming movements performed by each species are listed in Tables 2 and 3. Terminology follows Valentine and Stouffer (in preparation). Since there are over 3,500 species of cockroaches, a few exceptions to the family patterns we present are to be expected.

Small and large species were maintained in 9 and $12 \mathrm{~cm}$ white cardboard medical specimen cups with clear plastic lids. Lightly crumpled paper provided cover, and bits of dog biscuits and small water-soaked cotton balls provided food and water. Cryptocercus punctulatus was maintained in a $9 \mathrm{~cm}$ cup containing pieces of the $\log$ in which it was discovered. This debris provided food and was lightly misted every other day.

Each common species was observed for at least four hours. The longer observation periods listed in Table 1 provided no additional behaviors. Monospecific groups of 5 to 7 individuals were observed for 10 minutes in the maintenance cup with the paper removed. Then, single roaches were observed for not less than 20 minutes. A new cup was used for each species. Species $20 \mathrm{~mm}$ long and larger were observed directly; those less than $15 \mathrm{~mm}$ were observed with a dissecting microscope. Observations were made at most hours of the day or night, either in artificial or existing natural light. In the cases of Blaberus craniifer and Cryptocercus punctulatus, the light was fitted with a red cellophane filter. After grooming behavior of groups and individuals had been recorded for at least four hours for a particular species, further grooming was elicited by dusting 3 to 5 roaches of each species with household flour and observing these individuals for an average of an additional 20 minutes. 
Table 1. Number of individuals and time spent observing each species

\begin{tabular}{|c|c|c|c|c|}
\hline & 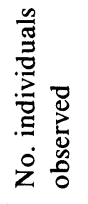 & 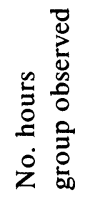 & 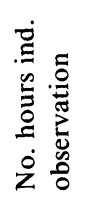 & 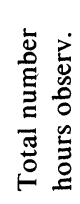 \\
\hline \multicolumn{5}{|l|}{ CRYPTOCERCIDAE } \\
\hline Cryptocercus punctulatus Scudder & 2 & 0 & 12 & 12 \\
\hline \multicolumn{5}{|l|}{$\begin{array}{l}\text { BLATTIDAE } \\
\text { Blattinae }\end{array}$} \\
\hline Blatta orientalis Linnaeus & 7 & 1 & 6 & 7 \\
\hline Periplaneta australasiae (Fabricius) & 6 & 1 & 5 & 6 \\
\hline Periplaneta brunnea Burmeister & 6 & 1 & 5 & 6 \\
\hline Periplaneta americana (Linnaeus) & 6 & 1 & 5 & 6 \\
\hline \multicolumn{5}{|l|}{$\begin{array}{l}\text { BLATTELLIDAE } \\
\text { Plecopterinae }\end{array}$} \\
\hline Supella longipalpa (Fabricius) & 7 & 1 & 6 & 7 \\
\hline \multicolumn{5}{|l|}{ Blattellinae } \\
\hline Blattella germanica (Linnaeus) & 7 & 1 & 6 & 7 \\
\hline Xestoblatta immaculata Hebard & 5 & 1 & 4 & 5 \\
\hline \multicolumn{5}{|l|}{ Nyctiborinae } \\
\hline Nyctibora lutzi Rehn \& Hebard & 6 & 1 & 5 & 6 \\
\hline \multicolumn{5}{|l|}{$\begin{array}{c}\text { BLABERIDAE } \\
\text { Zetoborinae }\end{array}$} \\
\hline Schultesia lampyridiformis Roth & 12 & 2 & 5 & 7 \\
\hline \multicolumn{5}{|l|}{ Blaberinae } \\
\hline Eublaberus posticus (Erichson) & 6 & 1 & 5 & 6 \\
\hline Archimandrita tessellata Rehn & 5 & 1 & 7 & 8 \\
\hline Byrsotria fumigata (Guèrin) & 4 & 3 & 0 & 3 \\
\hline Blaberus craniifer Burmeister & 4 & 2 & 8 & 10 \\
\hline \multicolumn{5}{|l|}{ Pycnoscelinae } \\
\hline Pycnoscelus indicus (Fabricius) & 6 & 1 & 4 & 5 \\
\hline Pycnoscelus surinamensis (Linnaeus) & 8 & 2 & 6 & 8 \\
\hline \multicolumn{5}{|l|}{ Diplopterinae } \\
\hline Diploptera punctata (Eschscholtz) & 7 & 2 & 5 & 7 \\
\hline \multicolumn{5}{|l|}{ Panchlorinae } \\
\hline Panchlora nivea (Linnaeus) & $\sim 30$ & 3 & 0 & 3 \\
\hline \multicolumn{5}{|l|}{ Oxyhaloinae } \\
\hline Leucophaea maderae (Fabricius) & 12 & 3 & 8 & 11 \\
\hline Nauphoeta cinerea (Olivier) & 7 & 1 & 6 & 7 \\
\hline Jagrehnia madecassa (Saussure) & 6 & 1 & 4 & 5 \\
\hline Gromphadorhina portentosa (Schaum) & 6 & 2 & 8 & 10 \\
\hline \multicolumn{5}{|l|}{ Perisphaeriinae } \\
\hline Gyna sculpturata Shelford & $\sim 24$ & 2 & 0 & 2 \\
\hline & & 34 & 116 & 154 \\
\hline
\end{tabular}




\section{RESULTS}

CLEANING. Involves chewing movements of the mouthparts.

Antenna Clean: Two major modes of antenna cleaning were observed: Assisted and Unassisted. The Assisted mode is subdivided into three submodes: Bipedal, Contralateral, and Ipsilateral.

1. Assisted.

a) Bipedal: This movement was observed only in Periplaneta brunnea of the family Blattidae. Both forelegs simultaneously move upward and grasp one antenna as it and the head are bent downward. The head is then raised and the antenna pulled into the mouth by the crossed forelegs.

b) Contralateral: This movement was confined to and observed throughout the families Cryptocercidae, Blattidae, and Blattellidae. The antenna is deflected downward as the contralateral foreleg moves upward and contacts the antenna. The head is raised and the antenna is pulled into the mouth by the leg.

c) Ipsilateral: Alternating with Unassisted, this movement was observed exclusively in the family Blaberidae. It resembles Contralateral except that the ipsilateral foreleg is used.

2. Unassisted.

Alternating with Ipsilateral, this method was observed exclusively in the Blaberidae. The antenna deflects into the mouth using its intrinsic musculature. There is no leg assistance, but the antenna may occasionally be trapped against the substrate.

Once the antenna is in the mouth, two aspects of antenna cleaning are constant in all species: a single antenna is cleaned at a time, and in species assisting with the foreleg, the antenna is released by the leg as it is grasped by the mouthparts.

Palpus Clean: Palpal cleaning was observed in all species. The labial and maxillary palpi are cleaned similarly. A single palp is curled directly into the mouth from the normal resting position. Either the entire palp or only the tip is cleaned.

Leg Clean: With three exceptions, all species clean all three legs. Cryptocercus punctulatus performs no leg cleaning, and two species in the family Blaberidae, Pycnoscelus surinamensis and Leucophaea maderae, were never observed to clean the hindleg.

1. Foreleg Clean: A foreleg is raised and extended forward as the head turns to reach it. The body is supported in a normal resting position by the remaining five legs. The mouthparts contact the leg 
at any point and clean it by slowly chewing from the point of contact to the end of the tarsus.

2. Midleg Clean: As the ipsilateral foreleg is raised and the head turned backward, a midleg is raised and extended forward under the body and raised foreleg. The body is supported by the ipsilateral hindleg positioned slightly farther forward than usual, the three opposite legs, and sometimes by the side of the abdomen.

3. Hindleg Clean: This movement resembles Midleg Clean. The foreleg is raised, followed closely by the midleg as the head dips down and back, and the hindleg swings forward underneath the raised fore- and midlegs. The tip of the abdomen is curled laterally toward the head, and the body is supported in a fourpoint stance by the curled abdomen and the three legs of the opposite side. If only the tibial apex or tarsus is cleaned, the midleg may remain in contact with the substrate.

Certain features are common to all leg cleaning in all species. The leg is usually raised from the substrate, and is always held ventrally. Movement of the leg relative to the head is always posterior, back and forth movement in the mouth did not occur. Cleaning may begin at any level from coxa to tarsus, and once begun continues from point of contact to the end of the tarsal claws. The leg or parts of the leg may be cleaned once or several times in succession. There is no set order for legs to be cleaned, and leg cleaning may be interspersed with grooming of other body parts.

Body Clean: Grooming the body with the mouthparts has only two modes in roaches.

1. Sternum Clean: Sternal cleaning is well-distributed throughout the families and genera (see Table 2). The body is slightly raised by extension of the legs, and the forelegs are widely spaced. The head bends down under the body until the mouthparts reach the coxae of the forelegs. These and the area between them are cleaned. Similar cleaning of the sternal and coxal area of the meso- and metathorax did not occur.

2. Pronotum or Wing Edge Clean: This is a much rarer movement than Sternum Clean, and was observed infrequently in only six species (see Table 2). The head is turned to the side and either the edge of the pronotum or the wing base just behind it is cleaned.

RUBBING. Involves progressive contact of body parts with other parts, or rarely, with the substrate. 


\begin{tabular}{|c|c|c|c|c|c|c|c|}
\hline & 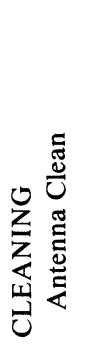 & 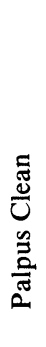 & $\begin{array}{l}\text { Eี } \\
\stackrel{\Xi}{U} \\
00 \\
\frac{0}{0} \\
0 \\
0 \\
\text { I. }\end{array}$ & 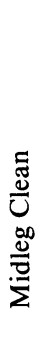 & 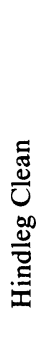 & 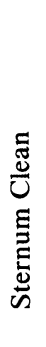 & 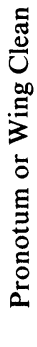 \\
\hline \multicolumn{8}{|l|}{ CRYPTOCERCIDAE } \\
\hline Cryptocercus punctulatus & $\mathrm{C}$ & $\mathbf{x}$ & & & & & \\
\hline \multicolumn{8}{|l|}{ BLATTIDAE } \\
\hline Blatta orientalis & $\mathrm{C}$ & $\mathbf{X}$ & $\mathrm{X}$ & $\mathbf{X}$ & $\mathbf{X}$ & & $\mathbf{X}$ \\
\hline Periplaneta australasiae & $\mathrm{C}$ & $\mathrm{x}$ & $\mathrm{x}$ & $\mathbf{x}$ & $\mathbf{x}$ & & \\
\hline Periplaneta brunnea & $\mathrm{B}, \mathrm{C}$ & $\mathrm{x}$ & $\mathbf{x}$ & $\mathrm{x}$ & $\mathbf{x}$ & & \\
\hline Periplaneta americana & $\mathrm{C}$ & $\mathrm{x}$ & $\mathbf{x}$ & $\mathbf{x}$ & $\mathbf{x}$ & & $*$ \\
\hline \multicolumn{8}{|l|}{ BLATTELLIDAE } \\
\hline Supella longipalpa & $\mathrm{C}$ & $\mathrm{x}$ & $\mathrm{x}$ & $\mathbf{x}$ & $\mathbf{x}$ & $\mathbf{x}$ & $\mathbf{x}$ \\
\hline Blattella germanica & $\mathrm{C}$ & $\mathbf{x}$ & $\mathrm{x}$ & $\mathrm{x}$ & $\mathbf{x}$ & $\mathbf{x}$ & \\
\hline Xestoblatta immaculata & $\mathrm{C}$ & $\mathrm{x}$ & $\mathrm{x}$ & $\mathbf{x}$ & $\mathbf{x}$ & & $\mathbf{x}$ \\
\hline Nyctibora lutzi & $\mathrm{C}$ & $\mathbf{x}$ & $\mathrm{x}$ & $\mathbf{x}$ & $\mathbf{x}$ & & $*$ \\
\hline \multicolumn{8}{|l|}{ BLABERIDAE } \\
\hline Schultesia lampyridiformis & $\mathrm{U}$ & $\mathbf{x}$ & $\mathbf{x}$ & $\mathbf{x}$ & $\mathrm{x}$ & $\mathbf{x}$ & \\
\hline Eublaberus posticus & $\mathrm{U}, \mathrm{I}$ & $\mathbf{x}$ & $\mathbf{x}$ & $\mathbf{x}$ & $\mathrm{x}$ & & \\
\hline Archimandrita tessellata & $\mathrm{U}, \mathrm{I}$ & $\mathbf{x}$ & $\mathbf{x}$ & $\mathrm{x}$ & $\mathbf{x}$ & & \\
\hline Byrsotria fumigata & $\mathrm{U}$ & $\mathrm{x}$ & $\mathrm{x}$ & $\mathrm{x}$ & $\mathbf{x}$ & & \\
\hline Blaberus craniifer & $\mathrm{U}$ & $\mathbf{x}$ & $\mathrm{x}$ & & & & $\mathbf{x}$ \\
\hline Pycnoscelus indicus & U,I & $\mathbf{x}$ & $\mathbf{x}$ & $\mathbf{x}$ & $\mathbf{x}$ & & \\
\hline Pycnoscelus surinamensis & $\mathrm{U}, \mathrm{I}$ & $\mathbf{x}$ & $\mathbf{x}$ & $\mathbf{x}$ & & $\mathbf{x}$ & \\
\hline Diploptera punctata & I & $\mathbf{x}$ & $\mathbf{x}$ & $\mathbf{x}$ & $\mathbf{x}$ & $*$ & \\
\hline Panchlora nivea & U,I & $\mathbf{x}$ & $\mathbf{x}$ & $\mathbf{x}$ & $\mathrm{x}$ & & \\
\hline Leucophaea maderae & I & $\mathbf{x}$ & $\mathbf{x}$ & $\mathbf{x}$ & & $\mathbf{x}$ & \\
\hline Nauphoeta cinerea & I & $\mathbf{x}$ & $\mathbf{x}$ & $\mathrm{x}$ & $\mathrm{x}$ & $\mathbf{x}$ & \\
\hline Jagrehnia madecassa & I & $\mathbf{x}$ & $\mathbf{x}$ & $\mathbf{x}$ & $\mathbf{x}$ & & \\
\hline Gromphadorhina portentosa & I & $\mathbf{x}$ & $\mathbf{x}$ & $\mathbf{x}$ & $\mathbf{x}$ & $\mathbf{x}$ & \\
\hline Gyna sculpturata & $\mathrm{U}$ & $\mathbf{x}$ & $\mathbf{x}$ & $\mathrm{x}$ & $\mathbf{x}$ & $\mathbf{x}$ & $\mathbf{x}$ \\
\hline
\end{tabular}

Note: U - unassisted

C - assisted -contralateral

I - assisted - ipsilateral

B - assisted - bilateral

*indicates movements performed only after application of flour 
Antenna-Foreleg Rub: This movement was performed by all species observed except $C$. punctulatus. The basal segments of the antenna not reached by the mouthparts during Antenna Clean are groomed by rubbing. The base of the antenna is caught in the crook of the tibio-femoral joint, and the foreleg very deliberately and slowly moves down in a scraping motion. This movement is often followed by Foreleg Clean, but is not consistently combined with Antenna Clean.

Head-Foreleg Rub: Two forms were observed (see Table 3).

1. Eye-Rub: This movement was observed in all species but $C$. punctulatus. The foreleg is raised and the area of the tibio-femoral joint contacts the eye just below the antennal base. The leg moves straight down in a short, sharp rub reaching most of the eye surface.

2. Low Face Rub: This movement was observed in all species. It is similar to Eye Rub, yet distinct. The area of the head contacted is restricted to the lateral mouth region.

Prothorax-Foreleg Rub: Individuals of a single species, Supella longipalpa, raise a foreleg so that the femur contacts the lateral margin of the prothorax and performs a quick series of two to five posterior strokes.

Abdomen-Hindleg Rub: This movement is well-distributed throughout the families. Only two blaberid species, Archimandrita tessellata and Gromphadorhina portentosa, were not observed to perform some type of abdomen rub. Dr. Louis M. Roth, in a most useful review of this manuscript, informs us that some other blaberids omit abdomen or wing rubs. He points out that the bodies of Laxta females are often solidly caked with dirt, and the tegmina of Therea nuptialis have small setae which retain debris and make the insects less conspicuous.

A hindleg is used to rub the dorsal, ventral, and/or lateral surfaces of the abdomen. The movement is always unilateral: an insect may alternate sides rapidly, but only one hindleg ever touches the body at one time. The direction of the rub is posteriad. Often, but not consistently, abdomen rubbing is followed by hindleg cleaning.

Cercus-Hindleg Rub: Cercus rubbing is present in most of the species observed (Table 2). Cercus-Hindleg Rub is a separate and elaborate movement quite distinct from abdomen rubbing. The ipsilateral hindleg rubs any part of the cercus; at times, only the very tip. The abdomen may or may not be curled toward the rubbing leg. 
Table 3. Rubbing and positioning movements of roaches

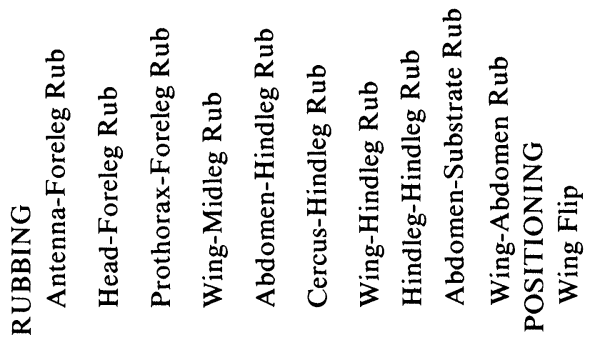

CRYPTOCERCIDAE

Cryptocercus punctulatus

X

X

\section{BLATTIDAE}

Blatta orientalis

Periplaneta australasiae

Periplaneta brunnea

Periplaneta americana

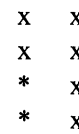

$\mathrm{X}$ X

X

X $\mathrm{X}$

$\mathrm{x} \quad \mathrm{x}$

$\mathrm{X} \quad \mathrm{X}$

* $\mathrm{X}$

$\mathrm{x} \quad \mathrm{x}$

X

BLATTELLIDAE

Supella longipalpa

Blattella germanica

Xestoblatta immaculata

Nyctibora lutzi

$\begin{array}{lllllllll}\mathrm{X} & \mathrm{X} & \mathrm{X} & \mathrm{X} & \mathrm{X} & \mathrm{X} & \mathrm{X} & \mathrm{X} & \\ \mathrm{X} & \mathrm{X} & & \mathrm{X} & \mathrm{X} & \mathrm{X} & & & \mathrm{X} \\ \mathrm{X} & \mathrm{X} & & \mathrm{X} & \mathrm{X} & \mathrm{X} & & & \\ * & \mathrm{X} & & & \mathrm{X} & \mathrm{X} & * & & \end{array}$

BLABERIDAE

Schultesia lampyridiformis $\quad \mathrm{x} \quad \mathrm{x}$

Eublaberus posticus

Archimandrita tessellata $\quad \mathrm{x} \quad \mathrm{x}$

Byrsotria fumigata

Blaberus craniifer

Pycnoscelus indicus

Pycnoscelus surinamesis

Diploptera punctata

Panchlora nivea

Leucophaea maderae

Nauphoeta cinerea

Jagrehnia madecassa

Gromphadorhina portentosa

Gyna sculpturata
$\mathrm{X} \quad \mathrm{X}$

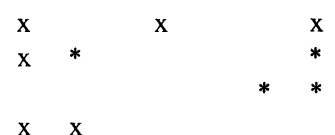

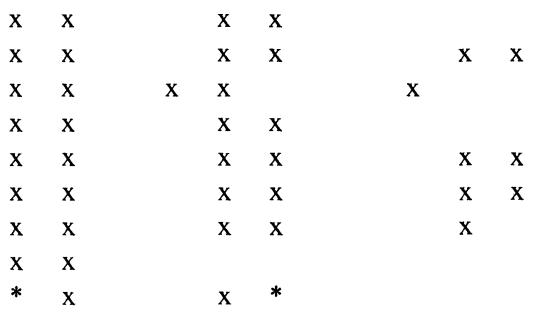


Some individuals of the more primitive species spend up to two minutes engaged solely in this grooming movement.

Abdomen-Substrate Rub: Two of the smaller species (length less than $15 \mathrm{~mm}$ ), Blattella germanica and Diploptera punctata, were observed to occasionally twist the abdomen sideways and drag the edge and part of the dorsal surface against the substrate. The wings are maintained in their normal position or raised a bit, resulting in only the abdomen contacting the substrate.

Hindleg-Hindleg Rub: Individuals of only two species, S. longipalpa and Schultesia lampyridiformis, place one hindleg slightly further under the body than normal and rub it several times from tibia to tarsus with rapid strokes of the tarsus of the opposite hindleg. Often the movement is reversed, and the other hindleg is rubbed similarly.

Wing-Hindleg Rub: A few individuals of three species, S. longipalpa, Nyctibora lutzi, and L. maderae, rub the dorsal surface of the closed wings with the tarsus of a hindleg, while the abdomen is in its normal resting position beneath the wings. This movement was always performed while Abdomen-Hindleg Rub was in progress.

Wing-Abdomen Rub: Several species in the families Blattellidae and Blaberidae (see Table 2) rub the underside of the closed wings vigorously and elaborately with the abdomen. There are four separate techniques. First, the abdomen may be rubbed from side to side in its normal position below the wings. Second, the abdomen may be flexed strongly, concave to the substrate, and the wings rubbed with only the central bent portion (of the abdomen). Third, the abdomen may be flexed strongly, convex to the substrate, and the tip of the abdomen rubbed in a circular or lateral motion against the underside of the wings. Finally the abdomen may be twisted so that only the lateral edge contacts the wings. When performed, these movements were almost always of longer duration than other grooming, and were usually performed between, or even during periods of extensive locomotion.

Wing Flip: In Blaberidae, a period of wing flipping was sometimes observed in conjunction with Wing-Abdomen Rub. The flipping could also be performed alone. Bouts last two to five minutes, with wings either flipped vertically or horizontally. 


\section{Discussion}

Prior to discussion of specific grooming movements, several generalized comments can be made regarding all species observed.

Except for Abdomen-Substrate Rub observed in two species, grooming in roaches is restricted to cleaning, or rubbing one body part with another. Other orthopteroids are known to utilize droplets of fluid in grooming (Allard, 1929). Though some individuals observed in this study placed droplets of clear fluid from the mouth onto the substrate, none utilized the droplet in grooming.

Though isolated grooming movements are often interspersed with periods of general activity, the most extensive and complete bouts are nearly always preceded by periods of relative quiet lasting two to seven minutes. No set sequence of grooming movements is discernible in any individual or species. Any combination or sequence of movements is possible, including repetitions of a particular movement. Larger species $(\geqslant 45 \mathrm{~mm})$ display a strong tendency to perform all grooming movements less frequently than the smaller species.

Generally, the use of flour as a stimulus has its greatest effect in simply increasing the frequency of movements in the next grooming bout. However, some species perform movements in the presence of flour which are not observed in its absence. Such movements are noted in Table 2 by an asterisk. Movements that are most consistently affected are basal antennal rubbing, abdomen rubbing, wingabdomen rubbing, and wing flipping.

An overall inhibiting factor is the presence of barometric low pressure. In advance of fronts and when under low pressure cells, all species exhibit a tendency to remain relatively quiet.

With a single exception, all species quickly became habituated to sunlight and artificial light. Grooming activity is readily performed at any hour of the day or night, even in bright light. Blaberus craniifer presents the single exception. In this species, the only grooming performed in daylight or lamplight was antenna and palp cleaning. Whether or not dusted with flour, when exposed to light the animal cleaned only the antennae and palpi, then arranged itself with the head, antennae, and legs drawn under the pronotum and wings, and sat unmoving until darkness fell or it was placed in a dark environment. During dark hours, the animal could be heard moving vigorously around the cup. On numerous occasions, the 
appearance of the roach's body the next day clearly indicated that leg cleaning and abdomen, cercus, and basal antenna rubbing had been performed. Using a red filter, two additional movements were observed: Foreleg and Pronotum Clean. Unfortunately, the single specimen died before a complete repertory was observed.

\section{Ordinal Patterns.}

The most striking characteristic of grooming in the order Blattaria is the remarkable stereotypy of the movements. In grooming a particular structure, one method usually suffices for all species. Despite varied habitats as living in loose sand, or flowers, or in bird nests (Roth, 1973), roaches groom legs, palpi, head, and abdomen in the same way.

Stereotyped methods and modes of grooming may be explained by considering the generalized anatomy of the group and the natural habitats of the species. The cockroaches are a very ancient order little changed in morphology since their time of dominance in the Carboniferous Period. Fossil and contemporary roaches are anatomically very similar. Since extant species are not substantially different in external morphology from either ancestral species or each other, there has been little or no pressure to evolve new grooming patterns to deal with specialized anatomical constraints. Also, roaches are cosmopolitan in their distribution and superficially diverse in their habitats. Unlike interstitial Diplura (Valentine and Glorioso, 1979), none of these habitats places undue physical restrictions on the animals. Roach habitats are cryptic, but none confines a species exclusively to cramped quarters, therefore there is no evidence for selection favoring open-ended and complex repertories like those of Diplura.

\section{Familial Patterns.}

Discussion of familial trends in grooming behavior lends greatest insight into roach phylogenetic relationships. Some differences exist at other taxomonic levels (Bobula, MS), but these are either inconsistent or based on small sample sizes.

The grooming movement most useful in interpreting blattarian phylogeny is Antenna Clean. Other movements form less clear patterns among groups and hence offer no aid in clarifying general phylogenetic relationships.

Based on trends in Antenna Clean, consistent familial differences exist between the families with generalized reproductive behaviors 
(Cryptocercidae, Blattidae, Blattellidae) and the more specialized Blaberidae. All roaches except the blaberids (the Polyphagidae were not sampled) assist antennae cleaning using the Contralateral mode. Individuals of each of the sampled species of Blaberidae, including a representative of the most primitive subfamily (Zetoborinae: Schultesia lampyridiformis) use either the Ipsilateral and/or Unassisted modes. No individual of any of the observed blaberid species used the Contralateral mode.

The constancy of this pattern seems highly significant. Apparently the Blaberidae are the most distinctive and cohesive family of roaches. The grooming data suggest that the Blaberidae, as numerous and superficially diverse as they are, form a specialized group clearly separate from the other roaches. This conclusion is in direct agreement with both McKittrick (1964) and Huber (1974).

The abrupt change in blaberid antennal grooming is probably tied to this recent evolutionary surge. The Blaberidae are the most recently evolved, most complex, most diverse cockroach family (Huber, 1974; McKittrick, 1964). If a new grooming movement were to evolve among the roaches, it would most logically appear, not in the groups which are the least changed from the ancestral forms, but in those which are the most changed, i.e., the Blaberidae. When available, the addition of polyphagid antenna cleaning behavior will further clarify the relationship of Blaberidae to the remaining families. If the mode used by Polyphagidae proves to be Contralateral, the Blaberidae would even more clearly appear to be a group apart.

It seems unlikely that Polyphagidae and Blaberidae will have similar antennal cleaning techniques. Polyphagidae is a primitive family, most closely related to the Blattellidae, while the Blaberidae devloped from a group which was already clearly separate from Polyphagidae (McKittrick, 1964). Thereafter, Blaberidae underwent extensive adaptive radiation, diverging even farther from their source group, and presumably from Polyphagidae. Any similarity of the Polyphagidae (a group which has not changed much from its ancestral forms) and the Blaberidae (a group very greatly changed) should be almost coincidental.

The monogeneric family Cryptocercidae forms a special case. Grooming movements recorded from $C$. punctulatus were the fewest of any species: a total of only four movements was recorded in more than twelve hours of observation. One individual of this species was put through two flour trials; neither yielded additional 
movements. After each flour application, as the roach was replaced in its culture cup, it immediately began to run in, under, and among the debris. This type of behavior was not observed when the roach was replaced without flour. After each flour trial, the greatest part of the flour was removed from the roach in less than one minute. Following the first flour trial, the roach was observed for 30 minutes (during which time no grooming was performed) and then removed and examined closely. Only minute specks of flour were visible on the ventral body surface. After the second flour trial, the period of heightened activity lasted seven minutes. As soon as the roach quieted it was removed and examined closely. The only remaining traces of flour were around the coxal bases. The roach was reexamined one-half hour later; this time, no traces of flour were found.

The most logical conclusion is that the flour was removed from the roach by contact with surrounding debris. Apparently the environment is a significant grooming tool for this species. When the two individuals studied were first collected from rotten logs they appeared very clean and shiny with no obvious adherent particles. Also, the cuticle had a bright shine unlike other roaches, and on handling, felt distinctly waxy. This suggests a special quality which makes it a poor site for adherent particles. Certainly if the roach can be free of fine flour within an hour after returning to its natural habitat, other particles could be similarly removed.

It is unlikely that the data obtained for Cryptocercus are skewed due to small sample size. Similar results were obtained from both individuals. Most important, the rapidity with which all flour was removed from the roach suggests that few grooming movements were recorded because few exist. The Cryptocercidae may in fact exhibit a case of evolutionary loss of grooming movements. With the development of a streamlined, waxy cuticle capable of shedding most particles, grooming would become an increasingly unnecessary part of the species behavior, and could easily be lost with no adverse effects on survival. If this is the case, it is interesting to note that the retention of antennal cleaning may be an indication of the importance of this sense organ.

\section{SUMMARY}

The grooming behavior of 23 species representing four families of Blattaria was recorded from 154 hours of observation. Specimens were initially observed in an undisturbed state. Several of each spe- 
cies were later dusted with household flour and further observed.

Grooming is performed by either Cleaning (passage through the mouth parts) or by Rubbing a structure with another body part or, rarely, the substrate. Palpi are curled into the mouth for cleaning. Antennae are cleaned by one of four techniques: Unassisted, in which the antenna deflects into the mouth by its own musculature, and three types of Assisted: Bipedal, in which both forelegs grasp one antenna and pull it into the mouth, Ipsilateral, assisted by the foreleg on the same side of the head as the antenna cleaned, and Contralateral, assisted by the opposite foreleg. Each leg is cleaned in one mode only; the leg is presented ventrally and pulled posteriad. Some species clean the sternum, and some turn the head sideways to clean the edge of the pronotum and/or tegmen.

All rubbing is unilaterally performed. Rubbing by the ipsilateral foreleg grooms the basal parts of the antennae not reached by the mouthparts, as well as the various head surfaces. The abdomen is extensively rubbed with the ipsilateral hindleg contacting the dorsal, ventral, or lateral edges. The cerci are similarly rubbed. The dorsal surface of the tegmen is occasionally rubbed with the ipsilateral hindleg. Flipping of the wings upward or outward occurs, usually while abdomen rubbing is in progress, but can also occur separately.

Several additional movements not generally characteristic of all Blattaria were infrequently performed by some species (these are included in Tables 2 and 3). Three blattellids and one blaberid occasionally rubbed the underside of the wing edge with the midleg, and one of these blattellids made similar movements with the foreleg against the underside of the pronotum. This same species and a blaberid performed hindleg-hindleg rubbing. Finally, two unrelated species, a blattellid and a blaberid, occasionally dragged the side of the abdomen against the substrate.

Grooming behavior is highly stereotyped in Blattaria. Except for Antenna Clean, a particular structure is groomed similarly by all species. Apparently, there has been no selection to evolve unique grooming structures nor positions that relate to the ecological differences of modern roaches. What works for one seems to work for all of those studied.

Cryptocercids form a special case since they have a very restricted repertory, but those grooming movements observed are performed as in other species. The minimal repertory of Cryptocercus may be a result of evolutionary loss of grooming movements, related to the 
development of a more waxy cuticle capable of shedding most particulates more efficiently than that of other roaches, or perhaps this species never evolved more complex grooming.

Antenna Clean is the grooming movement which clearly shows a distinction among roaches. The data suggest that the Blaberidae, though superficially diverse in morphology and habitat, form a specialized, cohesive group separate from other roaches. Cause for the change in mode of antennal cleaning may lie in the recent evolutionary surge of Blaberidae, but the actual selective pressures are not known.

The absence of data from the fifth family, Polyphagidae, is regrettable. Since they are the most primitive family of Blaberoidea, logically they should group with Cryptocercidae, Blattidae, and Blattellidae in antennal cleaning technique.

\section{ACKNOWLEDGMENTS}

Thanks to Stephen A. Smith for his assistance in collecting specimens of Cryptocercus punctulatus, to an unnamed reviewer who clarified various points, and especially to Dr. Louis M. Roth whose knowledge of Blattaria resulted in an outstanding review and many useful comments.

\section{Literature Cited}

Alexander, R. D.

1962. The role of behavioral study in cricket classification. Systematic Zoology 11: $53-72$.

AllaRd, H. A.

1929. The cleaning habits of a Katydid. American Naturalist 63: 283-288.

Bobula, B. J.

1979. Phylogenetic implications of grooming behavior in cockroaches (Insecta: Blattaria). M. S. Thesis. The Ohio State University.

BURKHOLDER, T. J.

1965. Effects of drugs on spontaneous activity of the central nervous system in the cockroach, Nauphoeta cinerea. M. S. Thesis. The Ohio State University.

Dow, R. P.

1955. A note on domestic cockroaches in south Texas. Journal of Economic Entomolgy 48: 106-107.

Eaton, R. C. and R. D. Farley.

1969. The neural control of cercal grooming behavior in the cockroach Periplaneta americana. Journal of Insect Physiology 15(6): 1047-1065. 
EISNER, T.

1961. Demonstration of a simple reflex behavior in decapitated cockroaches. Turtox News 39(8): 196-197.

Evans, H. E.

1953. Comparative ethology and the systematics of spider wasps. Systematic Zoology 2(4): 155-172.

FARISH, D. J.

1972. The evolutionary implications of qualitatative variation in the grooming behavior of the Hymenoptera (Insecta). Animal Behavior 20: 662-676.

GANGWERE, S. K.

1958. Grooming behavior in Orthoptera. Entomological News 69: 123-128.

Gould, G. E. AND H. O. Deay.

1938. The biology of the American cockroach. Annals of the Entomological Society of America 31: 489-498.

HABER, V. R.

1920. Oviposition by a cockroach, Periplaneta americana Linnaeus (Orthoptera). Entomological News 31: 190-193.

HEINZ, H. J.

1949. Beobachtungen über die Putzhandlugen bei Dipteren im allgemeinen und bei Sarcophaga carnaria L. im besonderen. Zeit. Tierpsychologie 6: 330-371.

HesLoP, J. P. AND J. W. Ray.

1959. The reaction of the cockroach, Periplaneta americana $\mathrm{L}$., to bodily stress and DDT. Journal of Insect Pathology 3: 395-401.

HUBER, I.

1974. Taxomonic and ontogenetic studies of cockroaches. The University of Kansas Science Bulletin 50(6): 233-332.

JANDER, U.

1966. Untersuchungen zür Stammesgeschichte von Putzbewegungen von Tracheaten. Zeit. Tierpsychologie 23(7): 799-844.

LIPPS, K. L.

1973. Comparative cleaning behavior in Drosophila. Ph.D. Dissertation. University of California, Davis.

MCKitTrick, F. A.

1964. Evolutionary studies of cockroaches. Cornell University Agricultural Experiment Station, Cornell Experiment Station Memoir 389. 198 pp.

Mote, D. C., J. Wilcox, AND E. G. Davis.

1926. The natural "cleaning up" habit of insects. Journal of Economic Entomology 19: 745-748.

Patton, D. B.

1941. Responses of three species of cockroaches to roach odors. M.S. Thesis. The Ohio State University.

QADRI, M. A. H.

1938. The life-history and growth of the cockroach Blatta orientalis Linnaeus. Bulletin of Entomological Research 29: 263-276. 
RAU, P.

1940. The life history of the American cockroach, Periplaneta americana Linnaeus (Orthoptera: Blattidae). Entomological News 51: 121-124, 151-155, 186-189, 223-227, 273-278.

Roth, L. M.

1973. Brazilian cockroaches found in birds' nests, with descriptions of new genera and species (Dictyoptera: Blattaria: Blaberidae and Blattellidae). Proceedings of the Entomological Society of Washington 75(1): 1-27.

Roth, L. M. AND E. R. WiLlis.

1952. A study of cockroach behavior. American Midland Naturalist 47(1): 66-129.

1954. The reproduction of cockroaches. Smithsonian Miscellaneous Collections, 22, No. 12.

SPEITH, H. T.

1952. Mating behavior within the genus Drosophila (Diptera). Bulletin of the American Museum of Natural History 99: 399-474.

SZYMANSKi, J. S.

1918. Abhandlungen zum Aufbau der Lehre von den Handlungen der Tiere. Pfluger's Archiv für gesamte Physiologie 170: 1-244.

TURNER, C. $\mathrm{H}$.

1913. Behavior of the common roach (Periplaneta orientalis L.) on an open maze. Biological Bulletin 25: 348-365.

VALENTINE, B. D.

1973. Grooming behavior in Coleoptera. The Coleopterist's Bulletin 27(2): 63-73.

Valentine, B. D. AND M. Glorioso.

1979. Grooming behavior in Diplura (Insecta: Apterygota). Psyche 85: 191-200.

VAlentine, B. D. and R. Stouffer.

In preparation. A terminology of grooming behavior in tracheate arthropods. YoshiKawa, K.

1958. Sanitary zoology of a Japanese cockroach, Periplaneta picea (Shiraki) with special reference to its ecological aspect. Journal of the Institute of the Polytechnics. Osaka City University Series D, 9: 77-103. 

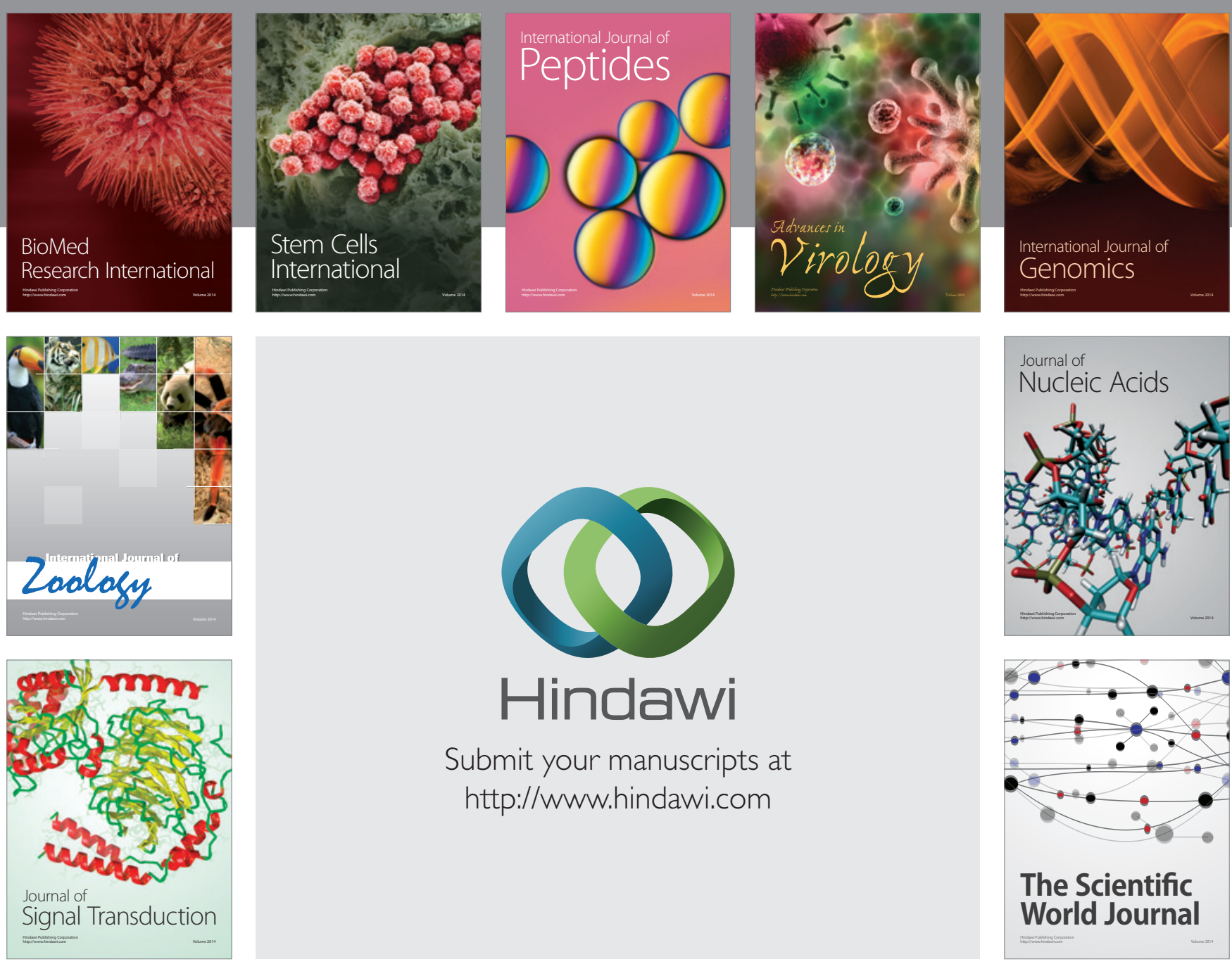

Submit your manuscripts at

http://www.hindawi.com
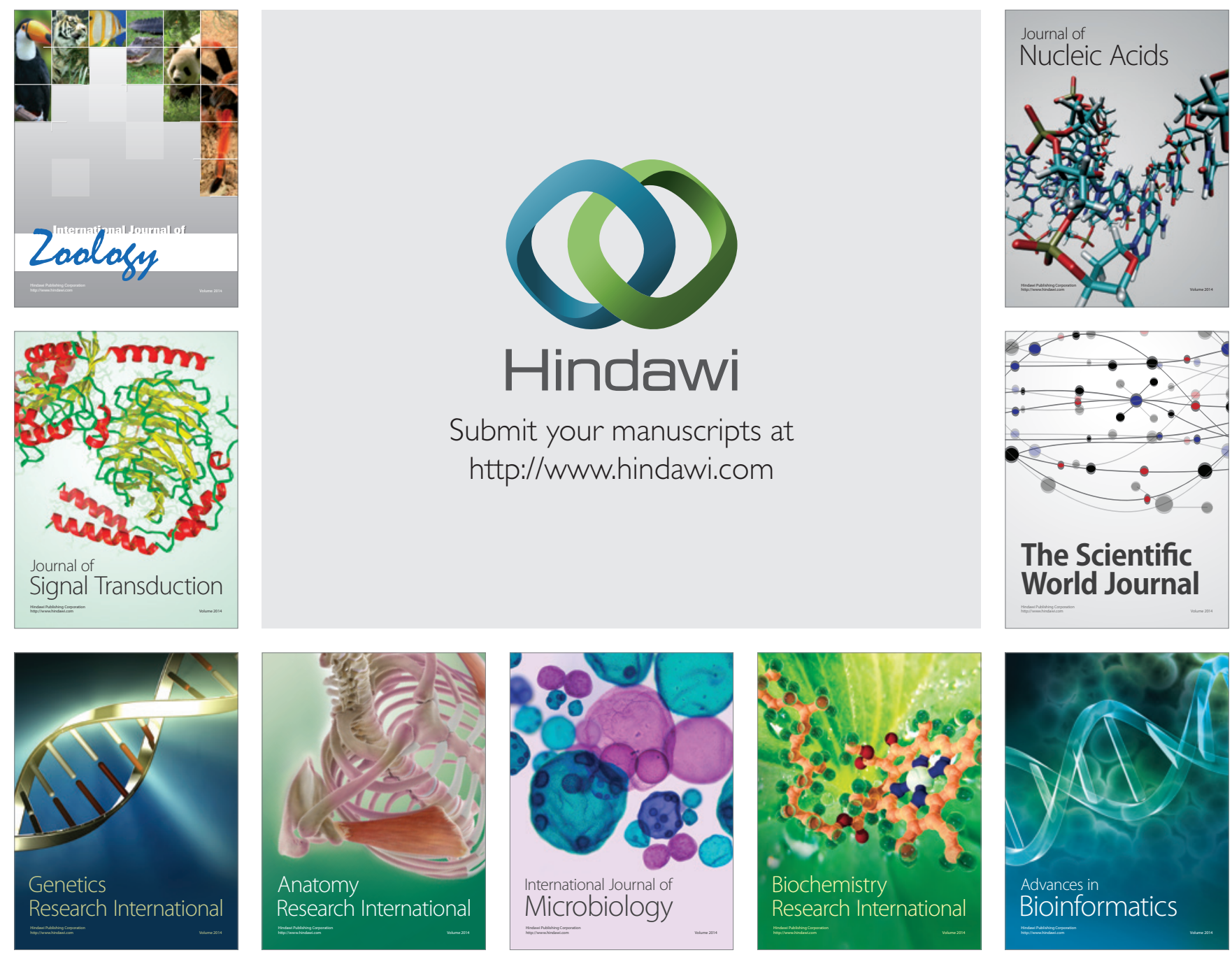

The Scientific World Journal
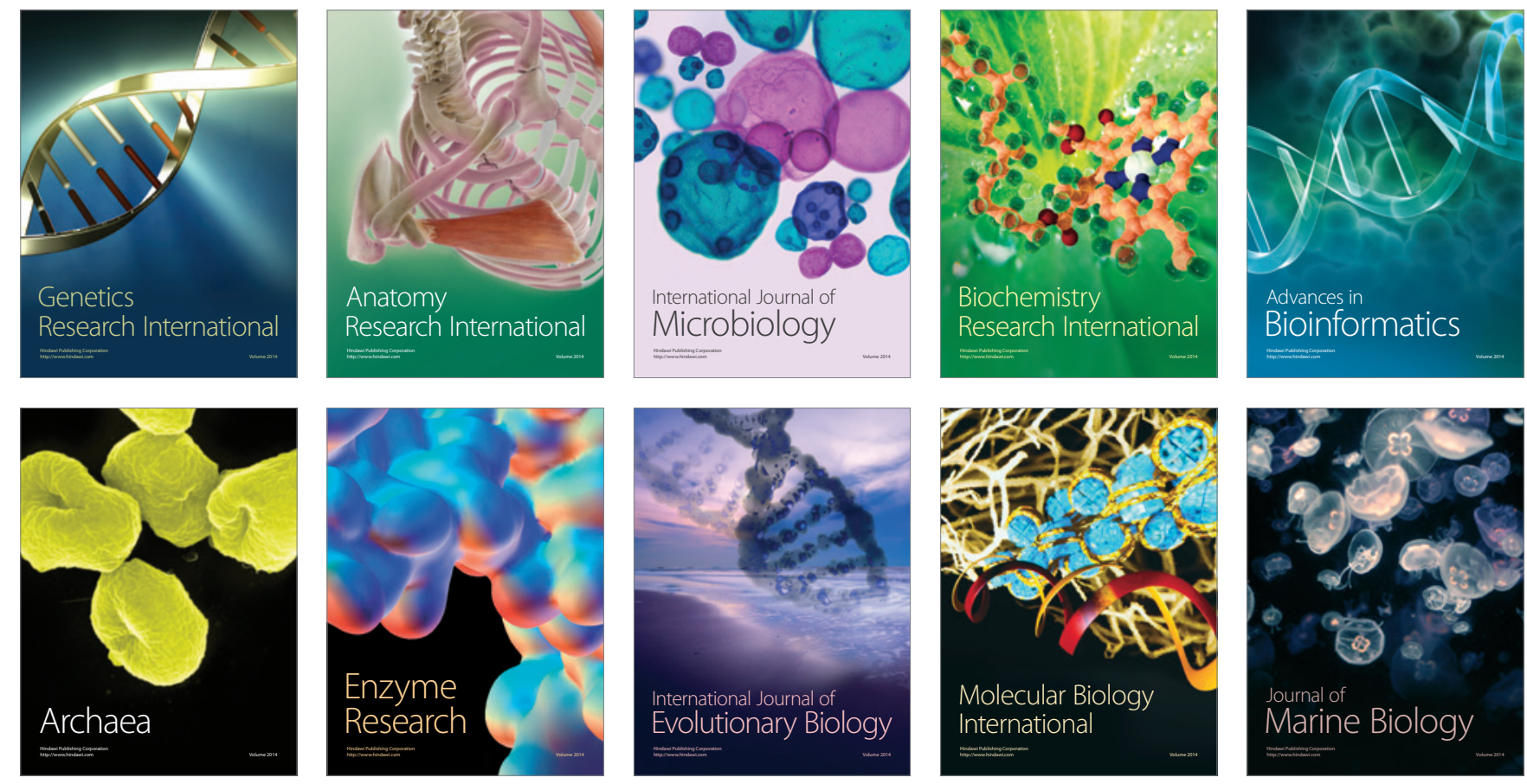